
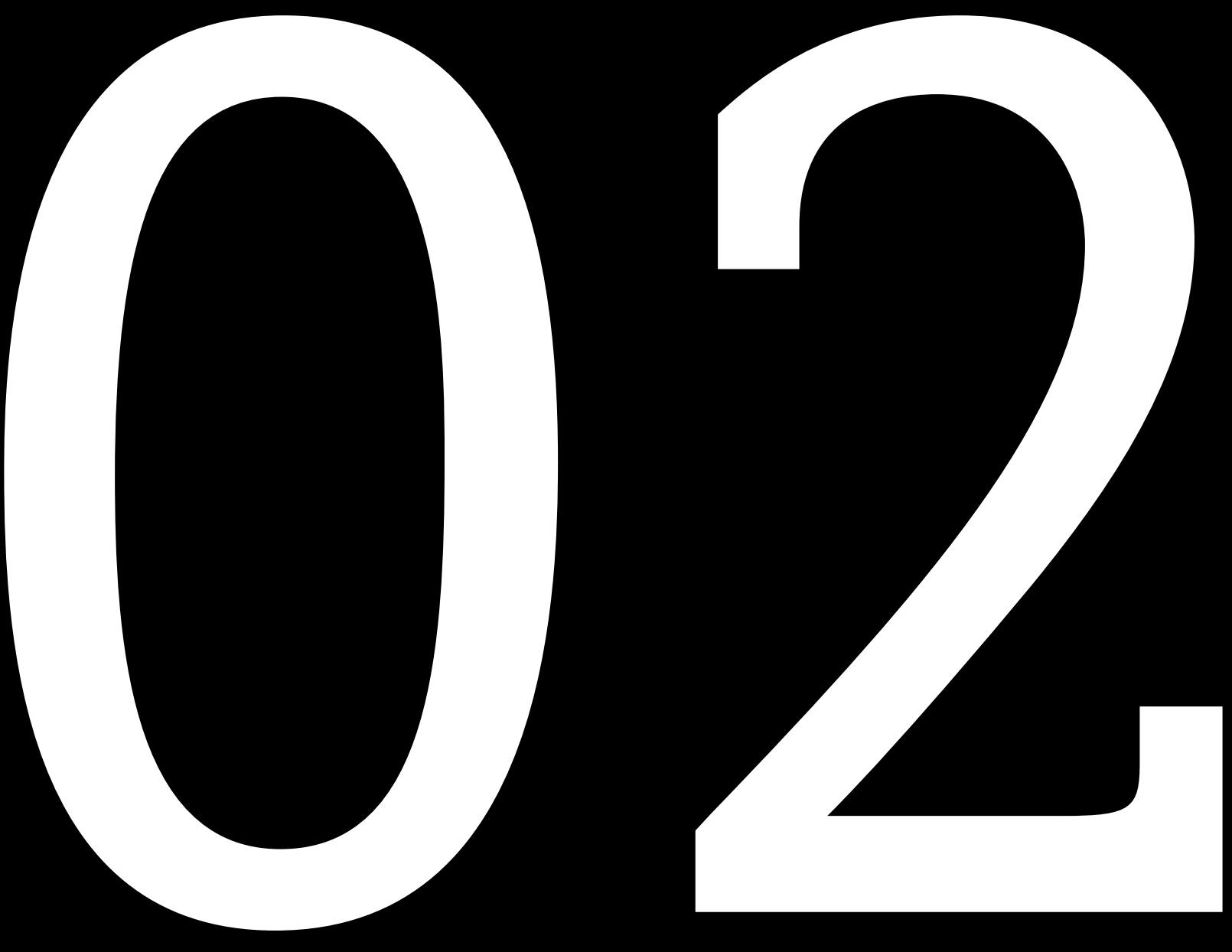

DOI: https://doi.org/10.14483/2422278X.14453 


\section{La voz de las familias en contextos de conflicto armado: emergencia de su dimensión política ${ }^{1}$}

The voice of the families on armed conflict contexts: emergency of its political dimension

\section{Cristina Álvarez Vargas ${ }^{2}$}

Fecha de recepción: 12 de julio de 2019

Fecha de aprobación: 4 de octubre de 2019

Para citar este artículo: Álvarez, C. (2020). La voz de las familias en contextos de conflicto armado: la emergencia de su dimensión política. Ciudad Paz-ando, 13(1), pp. 23-32

1 Este artículo de reflexión se deriva de la tesis doctoral: Experiencias de Crianza en Contextos de Conflicto Armado, realizado para optar el título de Doctora en Ciencias Sociales, Niñez y Juventud. Las instituciones que avalaron esta investigación fueron la Fundación CINDE y la Universidad de Manizales. Se realizó entre agosto de 2014 y febrero de 2018.

2 Psicóloga. Magíster en Psicología. Doctora en Ciencias Sociales, Niñez y Juventud. Docente Investigadora Fundación CINDE. Correo electrónico: calvarez@cinde.org.co ORCID: https://orcid.org/0000-0002-8991-8154 


\section{RESUMEN}

Este artículo tiene como objetivo reflexionar sobre la dimensión política de las familias en el contexto del conflicto armado colombiano desde sus propias experiencias. Se plantean los vínculos entre lo público y lo privado como escenarios que confluyen y que tienen fronteras cada vez menos visibles cuando se trata de abordar asuntos como la familia, sus configuraciones y prácticas “internas”, las cuales se han tratado convencionalmente como asuntos apolíticos. Este análisis va más allá de los marcos disciplinares tradicionales de la psicología o la medicina que, con frecuencia, han abordado el tema de la familia desde la lógica de la normalización y han producido un discurso sobre tipologías y clasificaciones más bien fijas, estables. Estos fenómenos son entendidos aquí más como construcciones sociales situadas que como asuntos universales, dándole un lugar protagónico a las formas como las familias resisten los hechos victimizantes propios de la guerra.

Palabras clave: conflicto armado, crianza del niño, familia, política pública.

\section{ABSTRACT}

This article aims to think about the political dimension of families in Colombian armed conflict context from their own experiences. The links are raised between private and public as converging scenarios and with less and less visible borders when is about treating matters like family, its configurations and "internal" practices, which had been conventionally treated as apolitical matters. This analysis goes further of traditional disciplinary frameworks of psychology or medicine that, frequently, have treated the family topic from the normalization logic and have produced a speech about rather fixed, stable typologies and classifications. These phenomena, in here, are understood more as besieged social constructions than as universal matters, giving a protagonist place to the shapes as the families resisting victimizing facts typical of the war.

Keywords: armed conflict, child rearing, family, public politics. 


\section{Introducción}

Hablar de lo político en niños y niñas ha tenido entradas muy interesantes y diversas en las ciencias sociales; además, en el contexto latinoamericano hay autores que han profundizado el tema desde diversas aristas (Alvarado et al., 2012; Schuch, 2009; Carli, 2002). Sin embargo, hablar de la familia desde lo público y lo político es una entrada poco explorada, dado que tradicionalmente se ha concebido como un asunto del orden privado. Un ejemplo de ello puede ser la Ley 1361 del 3 de diciembre de $2009^{3}$ que aún rige en Colombia, pues define la familia como: "el núcleo fundamental de la sociedad. Se constituye por vínculos naturales o jurídicos, por la decisión libre de un hombre y una mujer de contraer matrimonio o por la voluntad responsable de conformarla". No se señala el vínculo con estructuras más amplias de la sociedad ni configuraciones alternas a la unión heterosexual.

Asimismo, Guío (2009) plantea que la familia en Colombia es la institución más importante en el ordenamiento jurídico para determinar los aspectos que deben ser protegidos en el orden de lo privado. Desde concepciones disciplinares, "la familia ha sido el lugar primordial donde se comparten y gestionan los riesgos sociales de sus miembros" (Carbonell, 2005, p. 4, citado por Oliva y Villa, 2014, p. 12), evidenciando este y muchos otros trabajos que la familia es el lugar de los afectos y asuntos íntimos y que está poco influenciada por asuntos de orden estatal o macrosocial. Arendt (2005) lo plantea así: "La distinción entre esfera privada y pública de la vida corresponde al campo familiar y político, que han existido como entidades diferenciadas y separadas al menos desde el surgimiento de la antigua ciudad-estado" (p. 54). Jiménez (2008) lo afirma de manera más clara, sosteniendo que la familia rápidamente pasó de ser expresión de lo privado a consolidarse como la esfera de lo íntimo y, en este sentido, como una institución que no estaba vinculada con las lógicas de la estructura social macro y sus tecnologías de gobierno, al decir de Foucault.

Sin embargo, en los últimos años esta colectividad ha sido ubicada en otro lugar, en la medida en que se considera como un sujeto colectivo de derechos (Franco y Sánchez; 2008; Galvis, 2009; Ministerio de Salud y Protección Social, 2012; Sánchez y Palacio, 2013). De hecho, la Alcaldía Mayor de Bogotá (2016) lo expone así: "para considerar a la familia como titular de derechos es necesario pensarla como sujeto colectivo interlocutor con el Estado en la gestión social y económica y no simplemente como espacio de socialización" (p. 13). A pesar de este nuevo lugar, aún subsisten una serie de contradicciones que se viven al interior de las familias como las que se enuncian en la propuesta de Política pública nacional para las familias colombianas (Ministerio

3 Por medio de la cual se crea la ley de protección integral a la familia. de Salud y Protección Social, 2012) —que a la fecha no ha sido legislada-:

La familia es responsable del bienestar de sus integrantes y del equilibrio social pero está ausente y es ignorada en la esfera pública. El Estado y la Sociedad no la tienen en cuenta para la definición de la política social, el orden económico la ignora [...].

El tiempo de la producción económica es hegemónico, el tiempo de la familia es secundario [...].

Las mujeres son titulares del derecho a la participación en los asuntos públicos, pero sus tiempos están comprometidos con el trabajo remunerado, el cuidado de las generaciones y el trabajo doméstico [...].

El ordenamiento jurídico consagra el modelo único de familia mientras que la realidad social da cuenta de la pluralidad y diversidad en su composición y constitución [...].

La tensión entre la vigencia de los derechos humanos de los integrantes del grupo familiar y la familia como agente interlocutor en los diferentes escenarios públicos y privados es también la paradoja entre el poder patriarcal y la igualdad y libertad de sus integrantes [...].

Desde las percepciones, los seres humanos sienten la familia como el lugar de los afectos, pero ella es también espacio de violencia y maltratos para sus integrantes. (Ministerio de Salud y Protección Social, 2012, p. 5)

Las contradicciones arriba citadas permiten pensar que en un contexto de conflicto armado como el que ha vivido el país en los últimos sesenta años el lugar público y político de las familias tiene retos interesantes, entre ellos la comprensión de las dinámicas internas de estos colectivos que dan lugar a formas de resistencia y afrontamiento de los diferentes hechos victimizantes a los que se han visto expuestas cotidianamente cuando se vive en medio de la guerra ${ }^{4} \mathrm{y}$ la vinculación de esas prácticas $\mathrm{y}$ formas de relacionamiento interno de las familias con las estructuras más macro de la sociedad. Allí, entonces, emerge una dimensión política de las prácticas familiares, como la crianza, que son sugerentes para pensar en la construcción de paz en época de posacuerdos, porque permite ubicarse en una mirada amplia sobre lo que hacen las familias para enfrentar condiciones adversas como las que plantea el conflicto armado.

Es precisamente en ese contexto en que se produce el análisis de este artículo. El conflicto armado colombiano ${ }^{5}$

4 Para efectos de este artículo, se entenderá conflicto armado y guerra como conceptos sinónimos, aunque no se desconoce que muchos autores hacen distinciones importantes sobre el asunto.

5 El conflicto armado colombiano se constituye en uno de los más largos en el mundo, el cual, aunque se negoció y se llegó a un acuerdo para el fin definitivo (La Habana, 2016), ha enfrentado crisis importantes en su implementación, lo que ha agudizado la polarización que sobre el tema existe en Colombia. Esto hace que se convierta en un 
ha impactado de manera significativa a toda la sociedad, aunque no haya conciencia generalizada de ese impacto y de lo que implica en la vida cotidiana, en las dinámicas sociales y culturales de las comunidades, los pueblos, las familias y la sociedad civil en general. Las mujeres, los hombres, los niños y las niñas han quedado en medio de un fuego cruzado que los vincula "al conflicto no por la vía de la adhesión social sino por la coerción o la victimización" (CNMH, 2013, p. 16). Así entonces, pensar en la dimensión política de las familias ${ }^{6}$ en este contexto particular tiene unas implicaciones cuando menos sugerentes para la reflexión.

En relación con el conflicto armado colombiano, la información que se ha producido y que ha sido recogida en informes, registros oficiales y académicos (Prieto, Rocha y Marín, 2014; CNMH, 2013; Gallego, 2013; CINEP/PPP, 2012; García, 2008; Amnistía Internacional, 2008; Coalico, 2007) se ha hecho desde diversas miradas, con diferentes fuentes y atendiendo a momentos muy diferentes de dicho conflicto, incluso bajo gobiernos con posturas radicalmente opuestas frente al mismo. Esta multiplicidad de voces ha subrayado el tema de las víctimas, el cual recientemente ha cobrado mucha más fuerza en los ámbitos políticos y sociales. Muchos de ellos insisten en que solo la reivindicación de sus voces permitirá conocer la verdadera magnitud de lo que ha ocurrido durante los últimos 60 años y solo por allí comenzará la reconstrucción del país (CNMH, 2013; Gallego, 2013; Sánchez, 2013).

El impacto del conflicto se materializa en cada uno de los integrantes de la familia, sin distinción de género o del rol que cumple al interior de ella (Segura, 2010); incluso cada uno de sus miembros puede sufrir diversos impactos al mismo tiempo: secuestro, viudez, muerte, amenaza, "lo que en conjunto erosiona la vida familiar y obliga al grupo a recomponerse por desmembramiento y por cambios en la estructura de las relaciones, en las funciones, en los roles y en el manejo de la autoridad" (Cifuentes, 2009, p. 89).

Por su parte, la familia ha sido comprendida desde diversas concepciones teóricas que tienen implicaciones directas en los abordajes que se hacen de ella. Siguiendo a Alvarado et al., (2012) existen diferencias importantes en los enfoques que van desde la idea de "la familia como célula de la sociedad" (p. 163) — tal como la ve el Estado colombiano que mantiene la idea del modelo nuclear, heterosexual y con fines de reproducción ${ }^{7}$-, hasta los

escenario complejo y multicausal que se ha venido transformado con el tiempo a medida que han cambiado también las características políticas, sociales y económicas del país.

6 Las familias a las que hace referencia este artículo fueron entrevistadas en el marco de la investigación Experiencias de crianza en contextos de conflicto armado y fueron familias que permanecieron en sus territorios en momentos en que se daban las confrontaciones propias del conflicto armado.

7 Ley 1361 de 2009, citada anteriormente, que es la que actualmente rige la política de familia en Colombia y que se denomina "Ley que se sustentan en la idea de la familia como "socias, corresponsables y promotoras de su propio desarrollo" (Salas, citado por Alvarado et al., 2012, p. 163). En este mismo sentido, autores más contemporáneos como Burin y Meler (1998) han planteado que hay que pensar la familia actual entre tensiones que se producen tanto en la alianza (entre la pareja) como en la relación de filiación (entre las generaciones). Asimismo, que "existe una relación entre la forma de familiarización y la organización social en su conjunto" (Burin y Meler, 1998, p. 53), tanto que la lectura elemental que se la ha dado a la expresión "la familia como célula básica de la sociedad" debe entenderse desde la mirada de las influencias que ejercen las instituciones sociales y la organización de la producción en los estilos familiares que prevalecen.

Donzelot (1998), por su parte, ha sido uno de los teóricos que ha señalado que la relación familia-Estado debe ser el punto nodal del estudio sociológico, dado que son las tensiones sociales las que dan lugar a la perspectiva actual de familia y no solo las configuraciones y vínculos al interior de estas. Finalmente, para resaltar la transformación del concepto de familia desde la teoría social, hay que mencionar a Anthony Giddens (2000), quien sostiene que los cambios que afectan la esfera familiar no se pueden localizar en un solo lugar. Dichos cambios tienen tal vez matices culturales, pero en la actualidad podría decirse que las variaciones en las configuraciones familiares se dan casi en cualquier lugar; tanto así que solo una minoría vive actualmente en lo que se podría llamar una "familia estándar" de los años 50. Así, "Emparejarse y desemparejarse son ahora una mejor descripción de la situación de la vida persona que el matrimonio y la familia" (Giddens, 2000, p. 72-73).

Por otro lado, la familia se plantea como un campo de actuación profesional, en el que esta y los profesionales que interactúan con ella se configuran en campos de fuerzas y luchas en el sentido en que lo utiliza Bourdieu:

un campo de fuerzas por las imposiciones que se establecen a los agentes sociales que se adentran en él y de luchas, cuando los diversos agentes, según las posiciones de poder que asumen, se enfrentan en ese campo de fuerzas para preservar lo instituido o para generar transformaciones. (Sánchez, 2009, p 2-3) Cierra cita

Bourdieu (2013) plantea que el término campo debe abocar a pensar relacionalmente, queriendo decir que estos se refieren a configuraciones de relaciones objetivas entre posiciones, definidas estas últimas por la situación

de Protección Integral a la Familia”. Si bien hay un documento más reciente, mencionado en este artículo, que se titula Política Pública para Nacional para las Familias Colombianas del Ministerio de Salud y Protección Social (2012), a la fecha esta última no ha sido sancionada ni legislada aún. 
actual y potencial que ocupan los agentes o las instituciones en las diferentes estructuras de poder. Tal como ocurre en la familia vista como campo hay luchas e historia, los agentes en su interior se relacionan siguiendo las reglas de ese juego, con diferentes grados de fuerza y distintas posibilidades de éxito. Vista de esta manera, la familia cobra una mayor complejidad, dado que se puede entender como un "juego potencialmente abierto, cuyos límites son fronteras dinámicas", lo que permite comprender las interacciones que la estructura social tiene con el campo familiar y, así, no entender sus problemáticas u opacidades como una inadecuación biográfica de sus integrantes, sino en relación con las tecnologías de gobierno de una estructura social determinada.

En otro sentido, hay que señalar las limitaciones de ubicar a la familia en el ámbito exclusivo de lo privado. Para esto, los planteamientos de Arendt (2005) sirven para comprender cómo es que lo privado/público son esferas entre las cuales se ha borrado la línea divisoria, ya que "pueblos y comunidades políticas se entienden a imagen de grandes familias cuyos asuntos cotidianos han de ser cuidados por una administración doméstica gigantesca y de alcance nacional" (p. 55). Con el surgimiento de la esfera social — que no es ni pública ni privada al decir de la autora-, "en el Mundo Moderno las dos esferas fluyen de manera constante la una sobre la otra, como olas de la nunca inactiva corriente del propio proceso de la vida" (p. 58). Entonces, cada vez es más notorio que esos límites entre lo público y lo privado se diluyen o, cuando menos, resultan confusos. Puntualmente, con las familias ocurre que se desdibujan en la medida en que no es suficiente con los recursos y capacidades internas que estas desarrollan para enfrentar sus tareas, sino que se requiere de condiciones que vienen del entorno político, social y económico para que ello se dé, además de que esos agentes externos están relacionados con las contingencias que les presenta la guerra.

Antes de desarrollar la reflexión objeto de este artículo, es importante mencionar en líneas generales el proceso de investigación que se llevó a cabo en el estudio que da origen a esta reflexión. La investigación Experiencias de crianza en contextos de conflicto armado se realizó bajo el paradigma cualitativo, desde la metodología de los estudios biográfico-narrativos. Se desarrolló bajo el método específico de historias de familia (Miller, 2000), el cual es un método que:

tiene su origen en la tradición cualitativa y biográfico-narrativa de los estudios en ciencias sociales, lenguaje, filosofía y educación, y que emplea herramientas interpretativas asociadas con la sociogénesis y las genealogías sociales abordadas por ciertas ramas de la sociología para comprender las permanencias y cambios de estas agrupaciones sociales. (Álvarez y Amador, 2017, p. 30)
Entre otros asuntos, es un método que permitió la construcción de memorias a partir de relatos individuales y colectivos de familias que vivían en territorios donde se producían acciones propias del conflicto armado en momentos en que ellas criaban a las generaciones más pequeñas. Asimismo, este método posibilitó la creación de puentes entre generaciones para ampliar la comprensión del pasado y los significados que las familias atribuían a sus experiencias, identificando relaciones, pero también rupturas en las maneras como cada miembro de ellas narra lo sucedido.

En el estudio participaron tres familias de diferentes lugares con organizaciones y arreglos familiares disímiles. Las características de las tres, además de querer narrar su experiencia de crianza en el contexto del conflicto armado, era que estuvieran viviendo en territorios donde se producían acciones propias del conflicto mientras criaban a las generaciones más pequeñas. Una familia provenía de Huisitó, Cauca (primera generación), luego en Lejanías, Meta (segunda generación) y, finalmente, en Ciudad Bolívar, Bogotá. La segunda familia es de Gómez Plata, Antioquia (las tres generaciones que participaron en el estudio han vivido en ese municipio siempre). La tercera familia es de San Carlos, Antioquia (las dos primeras generaciones se criaron allí) ${ }^{8}$.

\section{La familia en lo público: la denuncia de las familias}
Yo naci aquí y aqui me tengo que morir [...] De Gómez Plata no me sacan porque aqui mi mamá sacrificó aquí toda una vida [...] Mi familia se queda aqui [... y y aquí nos quedamos
Hijo, segunda generación, Gómez Plata, Antioquia

Es necesario subrayar de nuevo que las familias con las que se trabajó en el estudio de base son familias que vivieron y permanecieron en contextos donde el conflicto armado se estaba produciendo (no son familias víctimas del desplazamiento forzado, en el sentido en que lo define el $\mathrm{CNMH}^{9}$ ). Algunas de sus características son: se quedaron en los territorios viéndose obligadas a transformar sus lógicas relacionales, "estirando" sus límites, cambiando tiempos y espacios compartidos, y generando

8 Para más detalles de la investigación, se publicará una vez finalizados los requisitos del doctorado, en el repositorio de la Universidad de Manizales (aproximadamente en el mes de mayo de 2019).

9 El Centro Nacional de Memoria Histórica define el desplazamiento forzado como un fenómeno masivo, sistemático, de larga duración y vinculado en gran medida al control de territorios estratégicos. Más allá de la confrontación entre actores armados, existen intereses económicos y políticos que presionan el desalojo de la población civil de sus tierras y territorios. Además, se reconoce que existen intereses provenientes de sectores empresariales que también han contribuido a propiciar el desalojo y apropiación de importantes territorios (CNMH, 2013). 
otras formas de vivir la vida cotidiana, haciendo evidente en lo público su situación como una forma de denuncia y de resistencia. En síntesis, tuvieron "que modificar sus funciones y ampliar sus redes de relacionamiento social" (Alvarado et al., 2012, p. 162). El carácter público de las familias participantes se evidencia en denuncias o actos públicos que hicieron, evidenciadas en narrativas producidas por ellas como la que le da entrada a este apartado o como las siguientes:

Yo no esperé a que mataran a mis hermanos, me fui con ellos una noche, sin que nadie supiera y me los llevé a Medellín y luego a Cali. Después volví y expuse la situación con la familia y los vecinos [...] era una forma de decir que no iba a permitir que les pasara nada, sin que supieran en el pueblo lo que estaba sucediendo. (FSC, San Carlos, Antioquia)

\section{Otro ejemplo puede ser:}

Yo le dije, pues que vengan y acaben con todo, pero mi hijo no se lo llevan —la guerrilla- porque yo sé que es lo que pasa luego [...] vienen y acaban con todo... prefiero que me maten y que todo el mundo sepa que fue porque no dejé ir a mi hijo. (FD, Ciudad Bolívar, Bogotá D.C.)

La familia, como lo plantea Jelin (1994), es un espacio paradójico. Es un espacio de lo íntimo y del afecto, pero al mismo tiempo es un espacio donde se dan formas múltiples de violencia. En este sentido, la concepción de familia tiene unas repercusiones importantes en la manera como se hace público su accionar, desdibujándose cada vez más los límites con lo privado. Las lecturas de lo que hace una familia ya no quedan en el ámbito de la intimidad, sino que tienen repercusiones hacia fuera, dado que esas actuaciones denotan las luchas que han librado para enfrentar la adversidad. Las palabras que abren este apartado fueron dichas por una de las familias entrevistadas y referían que al hacer públicas las amenazas de las que fueron víctimas, su lugar frente al resto de la comunidad a la que pertenecen cambió. No solo lograron mantenerse allí, sino que generaron una red de solidaridad ${ }^{10}$ que surtió el efecto de protección, pero además de denuncia pública que permitió que otras familias hablaran de lo que les estaba sucediendo.

No obstante todo lo planteado anteriormente, es necesario decir que, desde el ámbito de las políticas públicas,

10 En casos como los de familias indígenas y afros que organizan su vida en comunidad es donde pueden encontrarse estos rasgos público-políticos de manera más contundente, dado que sus formas de asociación se producen en la lógica de la visibilización de sus particularidades culturales y sus apuestas por el reconocimiento por parte del Estado de estas particularidades, así como las denuncias que hacen en torno a las victimizaciones de las que han sido objeto como "minorías" étnicas y raciales, lo que les permite reivindicar su carácter de sujeto político. hay un desconocimiento de la familia como actor político que tiene la voz más autorizada frente a su propia situación:

Las políticas dirigidas a las familias aún carecen de una definición específica, de un campo bien delimitado y de una legitimidad evidente. Su diseño enfrenta diversas dificultades, en particular las tensiones entre intereses familiares y personales, así como el conflicto para equilibrar la autonomía y la libertad individuales con las responsabilidades familiares. (Arriagada, 2001, p. 6) Cierra cita

Lo anterior se expresa también en la forma como el Estado, desde la formulación de esas políticas públicas, intenta regular e intervenir las "problemáticas familiares" sin la reflexión consecuente de su injerencia en ellas. Y aunque "la privacidad de la familia aparece como justificación para limitar la intervención del Estado en esta esfera" (Arriagada, 2001, p. 11), se sigue homogenizando la actuación frente a las familias, lo que a su vez las despolitiza. El discurso de la intervención psicosocial, tal como es enunciado por diferentes organismos que "las intervienen" —el Estado, algunas ONG, los medios de comunicación-, le resta valor al carácter histórico y cultural de estos colectivos.

Aunque es importante reconocer que hay aproximaciones más contemporáneas desde enfoques psicosociales que incluyen las discusiones actuales sobre el género, desde miradas no patologizantes, el acervo de investigaciones consultadas para el estado del arte de la investigación que da lugar a esta reflexión estaban escritas desde esos marcos disciplinares. Así entonces, aquellas que han vivido directamente los enfrentamientos propios del conflicto armado colombiano son vistas como víctimas silentes y pasivas, y los problemas que enfrentan a su interior se entienden como la consecuencia apenas lógica de la inadecuación biográfica de sus integrantes, frente a lo cual se diseñan los programas de intervención y estrategias que invisibilizan y simplifican las complejas relaciones de las dinámicas familiares con la dinámica de la estructura macrosocial (esto ocurre con más frecuencia en las acciones desarrolladas por operadores del Estado).

En medio de todas las contradicciones mencionadas, pareciera que son cada vez más lejanos los tiempos en los que las familias actuaban solo "de puertas para adentro"; sus actuaciones tienen repercusiones en el espacio público, transformando la mirada pasiva y el lugar de grupo sobre el que se interviene. Las familias participantes en el estudio en mención, muestran formas diversas, incluso "atrevidas" de hacerle frente a la adversidad y a las formas de victimización a las que estuvieron expuestas, haciendo "aparecer lo inédito", en el decir de Arendt, como una forma de acción (propia de lo político) que hace aparecer en el escenario público formas innovadoras para irrumpir en procesos sociales e históricos. Así, en contextos de guerra 
como el colombiano, cada vez se encuentran más familias que han tejido redes que les han permitido permanecer allí de manera activa, propositiva, resistente y resiliente, procurando reconstruir sus vínculos ${ }^{11}$.

\section{Lo político en las familias: resistencias ante la adversidad}

La verdad yo no tenía tiempo para ir a hacer filas para recibir las ayudas del gobierno, entonces me meti a un proyecto productivo, hice capacitaciones, un curso de confecciones en el SENA y así fui consiguiendo una máquina de coser, otra y otra [...] Hoy en día eso hace parte de la Fundación que manejo con mi familia, en la que recibimos personas que llegan desplazadas a Bogotá [...] Hoy tenemos 250 personas inscritas. Hija, segunda generación, Ciudad Bolívar, Bogotá

Preguntarse por la dimensión política de las familias que han estado expuestas al conflicto armado implica pensar en las decisiones que tomaron, como la que plantea la narrativa que abre este apartado; también en las contingencias que enfrentaron, en las resistencias que generaron frente a la adversidad y las formas que encontraron para criar a sus niños y niñas en medio de cambios indeseados y de entornos inseguros y vulnerables. Este ejercicio permite reivindicar a las "familias víctimas" desde otras miradas: "la víctima como protagonista, como agente social que desafía el poder, que reclama y reivindica, y que desde ese lugar no solo sobrevive y se rescata a sí misma, sino que transforma y construye una sociedad nueva" (CNMH, 2013, p. 27).

Las familias entrevistadas para el estudio que dio lugar a este escrito relatan múltiples formas de autogestión con las que enfrentaron las vicisitudes propias del conflicto armado. Su trabajo es político y se hace para difundir un mensaje, manteniendo la memoria de un país. Muchas de las que vivieron de cerca las épocas más cruentas del conflicto armado se constituyen para sus territorios en referentes de dignidad y resistencia. En palabras del CNMH (2013):

El registro de estos actos de pervivencia, rescate y resistencia en medio del conflicto armado en Colombia es visto por quienes lo narran como un deber fundamental en la construcción de la memoria histórica sobre la guerra.... Esto quiere decir que es preciso mantener el registro de la devastación y explorar el por qué pasó, pero también el cómo se afrontó y resistió. Estas historias no

11 De la mano de redes que han desarrollado diferentes colectivos de mujeres en territorios azotados por los diversos actores del conflicto armado, son ejemplo de ello: la Red de Mujeres del Magdalena Medio; las Mujeres tejedoras de Sonsón en Antioquia; la Ruta Pacífica de las Mujeres, entre muchas otras. son necesariamente memorias victoriosas, sino más bien, memorias que, al reconstruir las víctimas y las comunidades como sujetos y colectivos que perviven, responden y resisten, cumplen un papel de dignificación. (p. 360)

Y es aquí donde podría decirse que se encuentra presente en toda su extensión la dimensión política de las familias, tal como lo entiende Jelin (1994) cuando habla sobre la unidad familiar al caracterizarla como:

una organización social, un microcosmos de relaciones de producción, reproducción y de distribución, con una estructura de poder y con fuertes componentes ideológicos y afectivos que cimientan esa organización y ayudan a su persistencia y reproducción, pero donde también hay bases estructurales de conflicto y lucha. (p. 9)

En esa dimensión política hay que resaltar, además, el rol que ha cumplido la mujer, especialmente los cambios que ha enfrentado como agente social, tanto en lo privado como en lo público, y que han sido claves para comprender el carácter político de las mismas, dado el impacto que han tenido en procesos de transformación macrosociales tales como: "los niveles de escolaridad alcanzados por la mujer, su inserción en el mercado laboral, la conciencia de sus derechos y sus potencialidades" (Pachón, 2007 , p. 153). En palabras de autoras feministas como Meler (2008), las luchas públicas de las mujeres están directamente vinculadas con los conflictos que afrontan las familias contemporáneas.

Todo lo anterior repercutió de manera significativa en la transformación de las relaciones de poder al interior de la familia, pero también fuera de esta (Palacio, 2009; Sánchez y Palacio, 2013; Catalá, 2015; SDP y Universidad de La Salle, 2016). Por esta vía, la de la emancipación de la mujer, las familias han comenzado a tener voz en los espacios públicos, posturas políticas frente a las regulaciones que llegan desde agentes externos, estatales en su mayoría, que no reconocen la diversidad en la que se configuran hoy día los colectivos familiares ${ }^{12}$. Sin embargo, esta participación es muy débil aún y no llega a impactar la formulación de políticas públicas que reconozcan dicha diversidad.

De manera especial, en dos de las familias entrevistas ese papel de la mujer fue fundamental, no solo para asegurar la protección de las generaciones más pequeñas frente a las vulneraciones de las que podrían ser víctimas, sino para comprender el acto de la crianza como un acto político, en la medida en que ellas promovían procesos

\footnotetext{
12 Un ejemplo importante es el de las madres de Soacha, las de los falsos positivos en Bogotá, que siguen en sus territorios a pesar de las amenazas y se convirtieron en actores políticos públicos, denunciando de diferentes maneras los falsos positivos donde murieron sus hijos, pero a quienes no se les da el estatuto político que tienen.
} 
de agenciamiento no solo en sus familias, sino en sus entornos. Voluntad, acción y decisión que involucra a otros, para resistir y hacerle frente a la adversidad, es un rasgo especialmente femenino que se pudo vislumbrar en este estudio.

La familia ha sido la piedra angular sobre la que se ha erigido la práctica relacional que es propia a los seres humanos, es el primer espacio donde se experimenta la contingencia, donde se aprende (o se debería aprender) que se es mortal, falible, sometido a los estragos de la negatividad, que siempre se encontrarán situaciones que no se entenderán completamente. Sin embargo, en muchas familias colombianas este aprendizaje se ha dado a la fuerza, por la acción de agentes externos que la han violentado y victimizado. Muchas de ellas viven constantemente la revictimización cuando, al optar por una postura política abierta, al denunciar y rechazar los hechos que las han vulnerado reivindicando sus derechos, son invisibilizadas o señaladas como "objetos de intervención".

A las familias se les asigna un alto valor desde el discurso estatal como el lugar privilegiado para el desarrollo y socialización de los individuos, pero ese lugar no es evidenciado en las políticas públicas que se han desarrollado en los diferentes países de Latinoamérica, especialmente en Colombia, donde la política pública actual que rige -mencionada anteriormente-, desconoce la diversidad que se da en las configuraciones y organizaciones familiares, especialmente en un contexto de conflicto armado como el que ha vivido el país en las últimas seis décadas.

En este sentido, y a pesar de transformaciones evidentes, las nuevas configuraciones y dinámicas familiares no han trascendido para ser pensadas en función de su interacción e interrelación con el Estado. Tal como lo plantean Acevedo y Lozano (2011):

La finalidad de los campos políticos y jurídicos además de otros entes interdisciplinarios, es el reconocimiento de todas estas nuevas configuraciones familiares, afianzando temas como autoridad, participación de la mujer y su autonomía, procesos de igualdad y equidad, de derechos y respeto. (p. 19)

Uno de los retos que se le plantean a la sociedad colombiana, a partir de la prolongada exposición al conflicto armado, ahora que hay unos acuerdos de paz firmados - $\mathrm{y}$ frente a una porción creciente de personas que los consideran un desacierto y que se debería volver atráses el lugar que tienen las víctimas en la reconstrucción del tejido social, y cómo las familias, entendidas como sujeto colectivo de derechos, tendrían que ser reconocidas desde:

el lugar de agencia de desarrollo y como tal, ser un agente de concertación y negociación, de manera conjunta con el Estado, las instituciones y las demás organi- zaciones sociales en la construcción o resignificación de una sociedad que dignifique la vida humana y los sujetos como actores protagónicos de la vida social. (Palacio, 2009, p. 48)

Ese reto implica la comprensión de las familias como colectivos políticos que, además de ser agentes de formación de niños, niñas y adolescentes, finalmente hacen su apuesta en la construcción de experiencias de vida que permitan la promoción de la diversidad y la diferencia, la negociación de los conflictos y la interacción permanente con el Estado y la sociedad en la que se encuentran inscritos. Este lugar de las familias tendría repercusiones importantes en la formación de sujetos con un proyecto de vida ciudadano y, a la vez, con una responsabilidad social compartida en un escenario de posacuerdo que convoca a todas las voces que han hecho parte de las vivencias de la guerra.

\section{Conclusiones}

A manera de cierre, que no pretende ser definitivo, sino delimitar algunas ideas en relación con la comprensión de la familia como actor político, especialmente de aquellas que vivieron el conflicto armado en el país y cuyas prácticas estuvieron atravesadas por la lógica de incertidumbre y fluidez que plantea la guerra, se propone aquí líneas de discusión y ampliación en futuras investigaciones. Lo primero, es decir que la dimensión política de las familias en contextos del conflicto armado se refiere a las apuestas que las familias hacen para conducir a las nuevas generaciones en la manera como conviven con los otros diferentes, que es un rasgo distintivo de la política. Esta dimensión se ve permeada por las características y particularidades de los contextos en los cuales viven estas familias, estos les posibilitan unas cosas, pero les impiden otras y, aun así, encuentran la manera de enfrentar la adversidad. Por último, esta dimensión política de las familias implica que no solo se ocupan de sus tareas de cuidado y crianza, que muchas veces tienen que hacer para la supervivencia, sino que posibilitan la humanización de quienes interactúan en esa tarea de doble vía que implica la crianza. Las familias se configuran en escenarios políticos porque allí se negocia, se establecen acuerdos, es posible encontrarse y también se tienen luchas de poder.

En segundo lugar, es necesario pensar en la diversidad de arreglos familiares que debieron hacer las familias mientras enfrentaban acciones propias del conflicto armado para cumplir, no solo con sus tareas de supervivencia, sino para encaminar a las generaciones más pequeñas hacia formas otras de estar en un mundo que les produce miedos y amenazas. Es una forma de introducir a los recién llegados a un mundo que tiene una gramática particular (en el decir de Mèlich, 2010) ante el cual les enseñan unas explicaciones, respuestas y valoraciones para comprender adónde llegan. 
En tercer lugar, esta dimensión política de las familias invita a pensar en la acción con otros (Arendt, 1997), una acción que no es planificada, pero que surge en la medida en que se requiere para poder afrontar la adversidad. Al no ser planificadas, estas acciones hacen "aparecer lo inédito", convocando el principio de natalidad propuesto también por Arendt (1997), que es "la matriz de todas las acciones, acto de ruptura con el pasado mediante la introducción de algo nuevo en el continuum temporal de la naturaleza, en la vida cotidiana" (pp. 19-20).

En cuarto lugar, si se reconoce como un rasgo distintivo de lo político el hecho de vivir con otros diferentes, tal vez las prácticas familiares, en particular las experiencias de crianza de estas familias, se configuren en el escenario por excelencia donde ello se aprende, con las ambigüedades propias de un espacio donde confluyen lo íntimo, lo afectivo, pero también las profundas diferencias que habitan, en tanto seres humanos, las relaciones de poder y de género que no son ajenas a lo que ocurre en la matriz social más amplia.

Finalmente, las familias en su actuar, en su interactuar, se configuran en escenarios políticos toda vez que allí se establecen acuerdos, hay encuentros con otros diferentes, se negocia significados, se tienen luchas de poder. Ahora, pensar todo lo anterior en contextos de conflicto armado, como el que se ha vivido durante las últimas cinco décadas en el país es, por decir lo menos, retador. Reconocer las formas otras en que esto se produce, y más aún darle voz a las familias que lo vivieron en carne propia, es un desafío que tiene que asumirse como sociedad si se quiere comprender, no solo cómo esto atraviesa y constituye en lo que hoy se es, sino cómo los relatos hechos desde los márgenes, las fronteras, las "minorías", invitan a pensar en la potencia de lo político como parte constitutiva de la construcción de una paz que realmente convoque a todos.

\section{Referencias}

Acevedo, A. y Lozano, B. (2011). Del patriarcado a un paradigma de derechos: Transformaciones de la familia en Colombia [Trabajo de grado, Universidad Católica de Pereira].

Alcaldía Mayor de Bogotá (2016). Familia sujeto colectivo de derechos. Rostros y rastros, razones para construir sociedad. http://www.sdp. gov.co/sites/default/files/fmlia_sujeto_dere_2016.pdf

Alvarado, S., Ospina, H., Quintero, M., Luna M., Ospina, M. y Patiño, J. (2012). Las escuelas como territorios de paz. Construcción social del niño y la niña en contextos de conflicto armado. CLACSO.

Álvarez, C. y Amador, J. (2017). Historias de familia. El marco ampliado de las historias de vida. Folios, Segunda Época, 46, 29-39.

Amnistía Internacional (2008). “'Déjennos en paz!”: la población civil, víctima del conflicto armado interno de Colombia. EDAI.

Arendt, H. (1997). ¿Qué es la política? Paidós.

Arendt, H. (2005). La condición humana. Paidós.
Arriagada, I. (2001). Familias latinoamericanas. Diagnóstico y políticas públicas en los inicios del nuevo siglo. CEPAL.

Bourdieu, P. (2013). La lógica de los campos: hábitus y capital. Entrevista realizada por Sociólogos. http://ssociologos.com/2013/06/23/ entrevista-a-pierre-bourdieu-la-logica-de-los-campos-habitus-y-capital/

Burin, M. y Meler, I. (1998). Género y familia. Poder, amor y sexualidad en la construcción de la subjetividad. Paidós.

Carli, S. (2002). Niñez, pedagogía y politica. Transformaciones de los discursos acerca de la infancia en la historia de la educación argentina entre 1880 y 1955. Miño y Dávila.

Catalá, C. (2015). La maternización de la sociedad: derechos reproductivos y salud primal. Ilemata, 7(18), 225-240.

Centro de Investigación y Educación Popular [CINEP/PPP] (2012). Conficto armado en Colombia durante 2011. Informe especial del CINEP/Programa por la Paz. http://www.rebelion.org/docs/152325.pdf

Centro Nacional de Memoria Histórica [CNMH] (2013). Resumen del informe ;Basta Ya! Memorias de guerra y dignidad. Autoedición.

Cifuentes, M. (2009). Familia y conflicto armado. Trabajo social, 2, 87-106.

Coalición contra la vinculación de niños, niñas y jóvenes al conflicto armado en Colombia [Coalico] (2007). Un camino por la escuela colombiana desde los derechos de la infancia y la adolescencia. Informe sobre la situación de niños, niñas y jóvenes de los departamentos de Chocó, Putumayo y Cauca, la región de la cosa Caribe y la Ciudad de Medellín. https://reliefweb.int/report/colombia/un-camino-por-la-escuela-colombiana-desde-los-derechos-de-la-infancia-y-la

Congreso de Colombia (2009). Ley 1361 de 2009. https://www.icbf. gov.co/cargues/avance/docs/ley_1361_2009.htm

Donzelot, J. (1998). La policía de las familias. Pretextos.

Franco, S. y Sánchez, G. (2008). Las familias: ¿un asunto de políticas públicas? Sociedad y Economía, 14, 85-107.

Gallego, M. (coord.). (2013). La ruta pacifica de las mujeres. Victimas del conflicto armado en Colombia. Ruta Pacífica de las Mujeres.

Galvis, L. (2009). Presencia de la familia en las politicas públicas.

García, M. (2008). El conflicto armado colombiano. ¿El fin del fin? Informe especial. CINEP.

Giddens, A. (2000). Un mundo desbocado. Los efectos de la globalización en nuestras vidas. Taurus.

Guío, R. (2009). El concepto de familia en la legislación y en la jurisprudencia de la Corte Constitucional colombiana. Studiositas, 4(3), 65-81.

Jelin, E. (1994). Las familias en América Latina. Familia siglo XXI. Ediciones de las Mujeres.

Jiménez, A. (2008). Historia de la infancia en Colombia: crianza, juego y socialización, 1968-1982. Anuario Colombiano de Historia Socialy de la Cultura, 35, 155-188.

Meler, I. (2008). Las familias. Subjetividad y procesos cognitivos, 12, 158-188. 
Mèlich, J. (2010). Ética de la compasión. Herder.

Miller, R. (2000). Researching Life Stories and Family Histories. Sage.

Ministerio de Salud y Protección Social (2012). Politica pública nacional para las familias colombianas 2012-2022. http:// www2.congreso.gob.pe/sicr/cendocbib/con4_uibd.nsf/CBA649DA5EBF221205257BF1007B8494/\$FILE/APolitica_Publica_Familias_Colombianas_2012_2022_(1).pdf

Oliva, E. y Villa, V. (2014). Hacia un concepto interdisciplinario de la familia en la globalización. Justicia Juris, 10(1), 11-20.

Pachón, X. (2007). La familia en Colombia a lo largo del siglo XX. http:// www.bdigital.unal.edu.co/1363/13/12CAPI11.pdf

Palacio, M. (2009). Los cambios y transformaciones en la familia. Una paradoja entre lo sólido y lo líquido. Revista Latinoamericana de Estudios de Familia, 1, 46-60.
Sánchez, E. (2013). Las disputas por la memoria. Las víctimas y su irrupción en la esfera pública. Medellín 2004-2010. Estudios politicos, 42, 61-84.

Sánchez, G. (2009). Las familias en el campo de actuación profesional [Ponencia]. VIII Conferencia Iberoamericana sobre Familias. II Conferencia Nacional sobre Familias: "Cuestión Social, Derechos Humanos y Políticas Familiares en Iberoamérica. Avances, Desafíos y Perspectivas", Ciudad Autónoma de Buenos Aires, Argentina.

Sánchez, G. y Palacio, M. (2013). Cuidado familiar, orden discursivo hegemónico y contrahegemónico. Revista Latinoamericana de Estudios de Familia, 5, 29-45.

Schuch, P. (2009). Práticas de justiça. Antropologia dos modos de governo da infância e juventude no contexto pós-ECA. UFRGS. 